CARDIOVASCULAR MEDICINE

\title{
General population based study of the impact of tricyclic and selective serotonin reuptake inhibitor antidepressants on the risk of acute myocardial infarction
}

\author{
L J Tata, J West, C Smith, P Farrington, T Card, L Smeeth, R Hubbard
}

Heart 2005;91:465-471. doi: 10.1136/hrt.2004.037457

See end of article for authors' affiliations

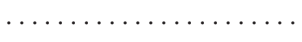

Correspondence to: Laila J Tata, Division of Epidemiology and Public Health, Clinical Sciences Building, Hucknall Road, Nottingham NG5 1PB, UK; laila.tata@nottingham. ac.uk

Accepted

2 November 2004
Objective: To investigate the impact of tricyclic antidepressants (TCAs) and selective serotonin reuptake inhibitors (SSRIs) on the risk of first acute myocardial infarction (MI).

Design: Case-control analysis and a self controlled case series.

Setting: 644 general practices throughout England, Scotland, Wales, and Northern Ireland.

Patients: Over 60000 cases of Ml and 360000 age, sex, and practice matched controls randomly selected from the UK General Practice Research Database.

Main outcome measures: Matched odds ratios and incidence rate ratios estimating whether there is an acute or prolonged increased risk of $\mathrm{MI}$ after exposure to TCA and SSRI drugs and individual drugs within these families.

Results: Case-control analysis found an initial increased risk of MI after TCA exposure (for example, at 1-7 days after the first dothiepin prescription: odds ratio (OR) 1.90,95\% confidence interval (CI) 1.15 to 3.14) or SSRI exposure (for example, at 1-7 days after first fluoxetine prescription: OR $2.59,95 \% \mathrm{Cl} 1.44$ to 4.66$)$. In the self controlled analysis the equivalent risk estimates were an incidence rate ratio of 1.43, $95 \% \mathrm{Cl} 0.92$ to 2.22 for dothiepin and an incidence rate ratio of $1.66,95 \% \mathrm{Cl} 1.01$ to 2.71 for fluoxetine. Conclusions: Antidepressant prescriptions are associated with an increased risk of MI. The size of these effects is similar for TCA and SSRI exposures; however, the lack of specificity between types of antidepressants and the lower risks found in the self controlled analysis suggest that these associations are more likely due to factors relating to underlying depression and health services utilisation than to specific adverse drug effects.
$M$ ore than $10 \%$ of older people in the UK are prescribed an antidepressant each year. While tricyclic antidepressants (TCAs) are most often prescribed, prescription rates for selective serotonin reuptake inhibitors (SSRIs) have increased rapidly over the past 10 years. ${ }^{1-4}$ The two families of antidepressant have a similar efficacy for the treatment of depression but SSRI antidepressants appear to be better tolerated. ${ }^{24-7}$ With respect to the cardiovascular system, TCAs are associated with decreased heart rate variability $^{8}$ and are cardiotoxic in overdose, ${ }^{9}$ whereas the antiplatelet effects of SSRI antidepressants mean that they may protect against cardiovascular disease or acute cardiovascular events. ${ }^{10-14}$ Findings of associations between antidepressant exposure and cardiovascular disease outcomes, however, have been inconsistent ${ }^{13}{ }^{15-21}$ and TCA drugs are still commonly prescribed to people at high cardiovascular risk. ${ }^{1722}$ One explanation for these different findings is that some studies have not been adequately powered to investigate the association of common individual antidepressants with the risk of acute myocardial infarction (MI). Furthermore, the possibility of additional confounding by depression as the underlying risk factor cannot be excluded, since depression has also been linked with ischaemic heart disease (IHD) and acute MI..$^{21}{ }^{23-26}$ Results of a previous case-control study of both TCA and SSRI drugs showed an increased risk of IHD with TCA exposure that was mostly attributable to dothiepin. ${ }^{20}$ Since IHD remains the most common cause of death in the UK and 5\% of the elderly are prescribed dothiepin each year, there is a pressing need to define more clearly the nature of these associations.

We analysed data from over 60000 cases of acute MI and over 360000 age, sex, and practice matched controls from the
UK General Practice Research Database (GPRD) to determine whether there is an increased risk of first MI after exposure to antidepressant drugs, whether any effects differ between types of individual antidepressant drugs, and whether the risk in an acute period after initial exposure differs from the remaining treatment period. We coupled the classic casecontrol analysis with the self controlled case series method to investigate and correct for the potential effect of bias and confounding in the classic approach.

\section{METHODS}

The UK GPRD

The UK GPRD contains the computerised longitudinal medical records for more than eight million people registered at over 700 general practices..$^{28}$ The data are anonymised and regularly audited. Participating general practices record over $95 \%$ of prescriptions. ${ }^{29}$ Independent studies have consistently found the validity of diagnoses, including acute MI, to be high. ${ }^{30-33}$

\section{Case-control analysis}

We identified all cases of first acute MI diagnosed between 1 August 1988 and 30 November 2001 in the GPRD records (diagnostic code list available from authors) and defined the date of this event as the index date. Patients were 18 years of age or older at the index date. For each case, we identified up to six controls who were contributing data at the case

Abbreviations: $\mathrm{Cl}$, confidence interval; GPRD, General Practice Research Database; IHD, ischaemic heart disease; MI, myocardial infarction; SSRI, selective serotonin reuptake inhibitor; TCA, tricyclic antidepressant 
patient's index date and who were also matched by sex, age, and general practice. We then extracted information on all prescriptions for antidepressant drugs before the index date. Antidepressant drugs were divided into SSRIs, TCAs, monoamine oxidase inhibitors, and "other antidepressants" drug families. We used conditional logistic regression (Stata release 8.0, StataCorp, College Station, Texas, USA) to estimate the effect of ever being exposed to an antidepressant drug on the risk of a first MI. We then assessed the impact of new exposures to the more common antidepressants with at least $1 \%$ exposure prevalence in the control group, TCAs, and SSRIs by obtaining odds ratios for first MI in relation to first prescription on the index date and at 1-7 days, 8-14 days, 15-21 days, 22-28 days, and more than 28 days before the index date. In multivariable analyses we examined the impact of possible confounding by body mass index, cigarette smoking, systolic blood pressure, diastolic blood pressure, antihypertensive drug exposure, hyperlipidaemic drug exposure, and a diagnosis of diabetes, retaining only those covariates that changed the estimated odds ratio by $5 \%$ or more. Multivariable analyses were repeated for individual antidepressant drugs with an exposure prevalence of at least $1 \%$ in the control group.

\section{Case series analysis}

The self controlled case series design estimates relative incidence of an outcome in high risk compared with low risk periods within person based only on data from cases. Originally developed to assess vaccine safety, it is useful for investigating the short term impact of drug exposures on the risk of acute outcomes, since it eliminates problems of interindividual confounding, such as the extent of coronary artery disease. ${ }^{34}$

Considering only cases with at least one exposure to antidepressant drugs, we extracted all prescriptions for antidepressants before and after their first MI. We assessed the acute, prolonged, and withdrawal effects of antidepressant drugs by quantifying the relative incidence of first acute MI in predefined risk periods of drug exposure, compared with the patient's unexposed time (fig 1). Periods of acute risk were defined as the day of first prescription (0), 1-7 days, 8-14 days, 15-21 days, and 22-28 days after first prescriptions to mimic the case-control analysis. A period of remaining exposure was defined as 29 days after the patient's first prescription until 28 days after the last prescription, during which time patients never had more than 58 days between prescriptions (twice the median time between prescriptions). The last risk period of 29-56 days after the last prescription was designed to represent a period of drug withdrawal. All remaining person-time, when the patient was not exposed to an antidepressant drug, contributed to the baseline incidence.

With GLIM version 4.09 software, we conducted conditional Poisson regression to estimate incidence rate ratios, adjusted for age at first MI in five year bands. We assessed the impact of SSRI and TCA drugs and the individual drugs within these families as investigated in the case-control analysis.

\section{RESULTS}

We identified 63512 cases of first MI and 378886 controls. Cases and controls contributed a median of 2.4 years (interquartile range $0.5-13.3$ years) of data before the case patient's first MI. The mean (SD) age of the cases at first MI was 70.9 (12.4) years, $72 \%$ were between $50-80$ years of age, and the majority of cases $(61 \%)$ were men (table 1). Current smokers accounted for $27 \%$ of cases compared with $18 \%$ of controls, and first MI was associated with smoking habit in a test for trend comparing current, former, and non-smokers $(\mathrm{p}<0.01)$. Increased body mass index and systolic and diastolic blood pressures were all risk factors for first MI. Cases were more likely to have a prescription for antihypertensive or hyperlipidaemic drugs prescribed before their first MI and to have diabetes diagnosed (table 1).

The prevalence of SSRI and TCA prescribing was $2.8 \%$ and $8.9 \%$, respectively, for the controls, whereas it was only $0.1 \%$ and $0.6 \%$ for monoamine oxidase inhibitors and other antidepressants, respectively. Cases were more likely than controls to be exposed to an antidepressant drug in any drug family before the index date (table 2). This effect was marginally greater for exposure to an SSRI (crude odds ratio (OR) 1.49 , 95\% confidence interval (CI) 1.43 to 1.56) than for exposure to a TCA (crude OR 1.41, 95\% CI 1.37 to 1.45). Exposure to individual drugs within the SSRI and TCA families before the index date was also associated with an increased risk of first MI. Effects were similar between drugs-for example, the highest crude odds ratio was for fluoxetine exposure (OR 1.54, 95\% CI 1.45 to 1.64 ) and the lowest crude odds ratio was for dothiepin exposure (OR 1.33, 95\% CI 1.27 to 1.38). Inclusion of the possible confounding variables measured did not change the odds ratios by $5 \%$ or greater so only crude odds ratios are presented.

In our more detailed timing analysis of exposure, SSRI and TCA drugs were associated with acute increased risk of first MI when the first prescription was given less than 28 days before the index date (table 3 ). All five individual drugs were associated with acute increased risk of first MI when first prescribed on the index date and within 1-7, 8-14, 15-21, and 22-28 days of the index date; however, $95 \%$ CIs for some odds ratios included 1 . Odds ratios were unaffected when we

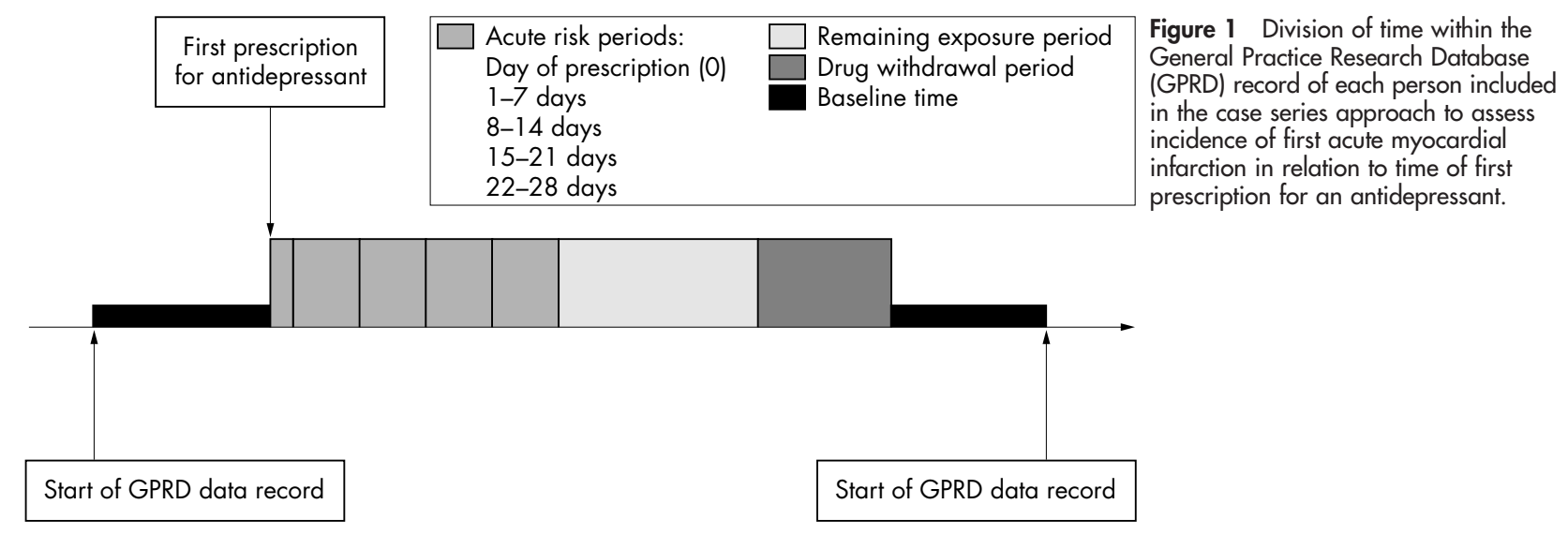




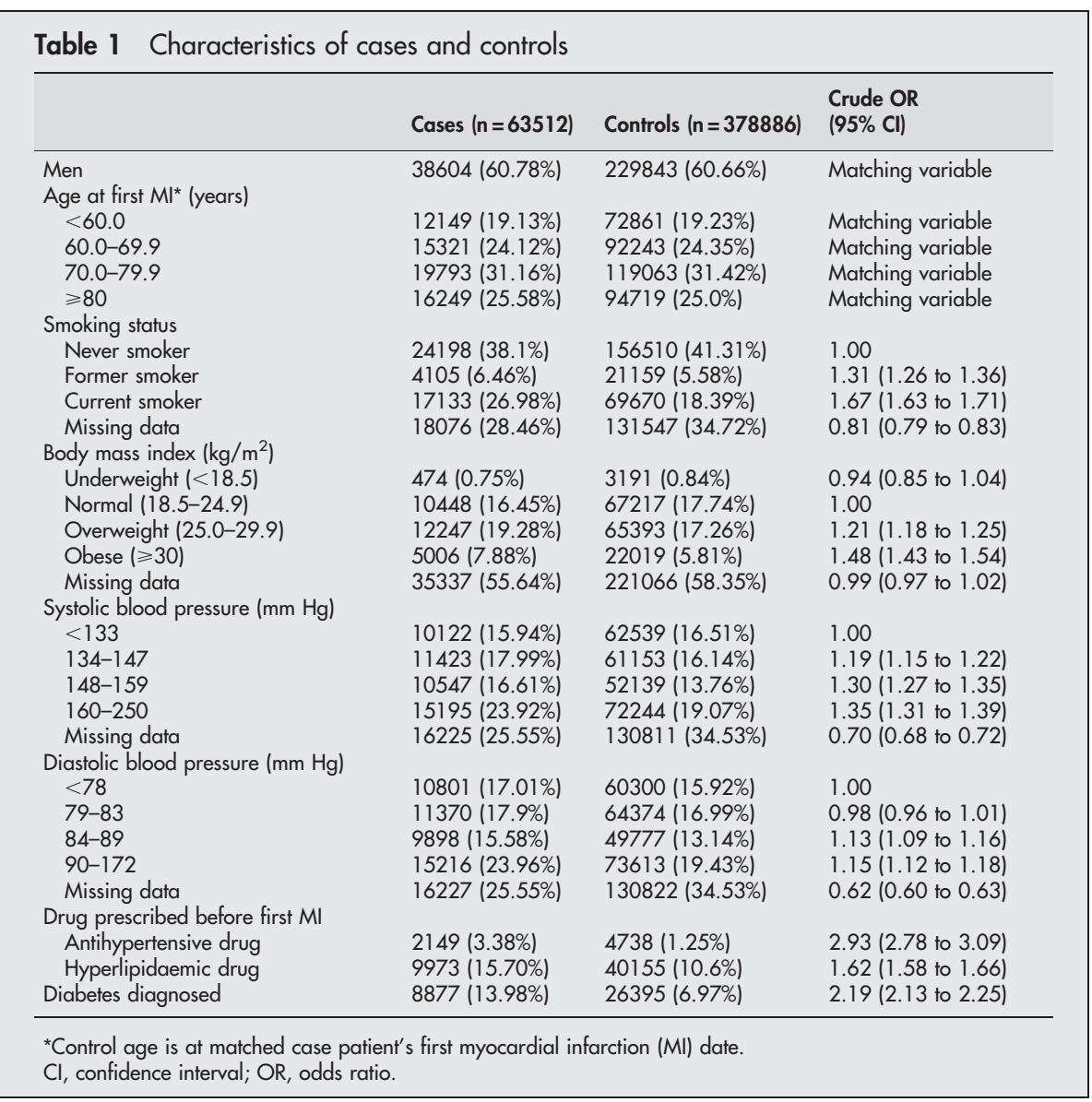

conducted sensitivity analyses by excluding patients with a prior history of vascular disease from the dataset and by excluding patients exposed to more than one antidepressant drug family (data not shown).

In the case series analysis, we identified 4132 (6.5\%) cases first exposed to an SSRI antidepressant and 6735 (10.6\%) cases first exposed to a TCA at some time point before or after their first MI (table 4). Of these, 1832 (44.3\%) SSRI exposed patients had only one SSRI prescription and 3291 (48.9\%) TCA exposed patients had only one TCA prescription. Mean age at first MI for these patients was similar to that of the whole population (63512 cases). Cases exposed to at least one SSRI contributed a median of 7.0 years (interquartile range 4.9-9.0) of data and those exposed to at least one TCA contributed a median of 5.9 years (interquartile range 3.78.5). Risk of first MI was increased during the acute risk periods (the day of first prescription and 1-7, 8-14, 15-21, and 22-28 days after first prescription) for both SSRI and
TCA drug families and for each individual drug (table 4), although the CIs for many incidence rate ratios included 1 . During the remaining exposure period all incidence rate ratios were close to 1 for both SSRI and TCA exposure, suggesting no evidence of an increased risk of first MI. During the withdrawal period (29-56 days after the last prescription) there was an increased risk of first MI for both SSRI and TCA drugs and this effect was similar across individual drugs.

\section{DISCUSSION}

In this large general population based sample, the results of our case-control analysis show that the use of antidepressants is associated with a transient increased risk of acute MI in the first 28 days after new antidepressant exposure. In the self controlled case series analysis, these increases were also present, but smaller, suggesting the presence of residual interperson confounding in the case-control analysis. The

Table 2 Case-control analysis: association between antidepressant exposure and first $\mathrm{MI}$

\begin{tabular}{llll}
\hline Drug exposure* & Cases $(\mathbf{n = 6 3 5 1 2 )}$ & Controls $(\mathbf{n = 3 7 8 8 8 6 )}$ & OR (95\% Cl) \\
\hline Any antidepressant & $9087(14.31 \%)$ & $40146(10.6 \%)$ & $1.43(1.40$ to 1.47$)$ \\
Any SSRI & $2549(4.01 \%)$ & $10439(2.76 \%)$ & $1.49(1.43$ to 1.56$)$ \\
Any TCA & $7587(11.95 \%)$ & $33726(8.90 \%)$ & $1.41(1.37$ to 1.45$)$ \\
Any MAOI & $87(0.14 \%)$ & $413(0.11 \%)$ & $1.26(1.00$ to 1.59$)$ \\
Any "other" & $491(0.77 \%)$ & $2121(0.56 \%)$ & $1.39(1.26$ to 1.54$)$ \\
Fluoxetine (SSRI) & $1327(2.09 \%)$ & $5225(1.38 \%)$ & $1.54(1.45$ to 1.64$)$ \\
Paroxetine (SSRI) & $870(1.37 \%)$ & $3839(1.01 \%)$ & $1.37(1.27$ to 1.47$)$ \\
Dothiepin (TCA) & $2926(4.61 \%)$ & $13431(3.54 \%)$ & $1.33(1.27$ to 1.38$)$ \\
Amitriptyline (TCA) & $2627(4.14 \%)$ & $11500(3.04 \%)$ & $1.39(1.33$ to 1.46$)$ \\
Lofepramine (TCA) & $1394(2.19 \%)$ & $5647(1.49 \%)$ & $1.49(1.41$ to 1.59$)$ \\
\hline
\end{tabular}

*At least one prescription before first $\mathrm{MI}$.

TCA, tricyclic antidepressant; MAOI, monoamine oxidase inhibitor; SSRI, selective serotonin reuptake inhibitor. 


\begin{tabular}{|c|c|c|c|}
\hline $\begin{array}{l}\text { First prescription } \\
\text { (days before first MI)* }\end{array}$ & $\begin{array}{l}\text { Cases } \\
(n=63512)\end{array}$ & $\begin{array}{l}\text { Controls } \\
(n=378886)\end{array}$ & OR $(95 \% \mathrm{Cl})$ \\
\hline \multicolumn{4}{|l|}{ SSRIs } \\
\hline \multicolumn{4}{|l|}{ Any SSRI } \\
\hline $0 \dagger$ & $13(0.02 \%)$ & $16(0 \%)$ & 4.96 (2.39 to 10.32 ) \\
\hline $1-7$ & $37(0.06 \%)$ & $84(0.02 \%)$ & $2.66(1.81$ to 3.92$)$ \\
\hline $8-14$ & $25(0.04 \%)$ & $83(0.02 \%)$ & $1.79(1.15$ to 2.81$)$ \\
\hline $15-21$ & $24(0.04 \%)$ & $79(0.02 \%)$ & $1.86(1.18$ to 2.95$)$ \\
\hline $22-28$ & $22(0.03 \%)$ & $80(0.02 \%)$ & 1.65 (1.03 to 2.65 ) \\
\hline$>28$ & 2428 (3.82\%) & $10097(2.66 \%)$ & $1.47(1.41$ to 1.54$)$ \\
\hline \multicolumn{4}{|l|}{ Fluoxetine } \\
\hline $0 \dagger$ & $10(0.02 \%)$ & $4(0 \%)$ & 15.09 (4.73 to 48.11$)$ \\
\hline $1-7$ & $16(0.03 \%)$ & $37(0.01 \%)$ & 2.59 (1. .44 to 4.66$)$ \\
\hline $8-14$ & $14(0.02 \%)$ & $43(0.01 \%)$ & 1.89 (1.03 to 3.48$)$ \\
\hline $15-21$ & $12(0.02 \%)$ & $35(0.01 \%)$ & 2.08 (1.08 to 4.01$)$ \\
\hline $22-28$ & $12(0.02 \%)$ & $44(0.01 \%)$ & 1.65 (0.87 to 3.12$)$ \\
\hline$>28$ & 1263 (1.99\%) & $5062(1.34 \%)$ & 1.51 (1.42 to 1.61$)$ \\
\hline \multicolumn{4}{|l|}{ Paroxetine } \\
\hline $0 \dagger$ & $3(0 \%)$ & $8(0 \%)$ & $2.29(0.61$ to 8.64$)$ \\
\hline $1-7$ & $18(0.03 \%)$ & $34(0.01 \%)$ & $3.18(1.80$ to 5.63$)$ \\
\hline $8-14$ & $11(0.02 \%)$ & $26(0.01 \%)$ & $2.56(1.26$ to 5.18$)$ \\
\hline $15-21$ & $11(0.02 \%)$ & $34(0.01 \%)$ & 1.95 (0.99 to 3.85$)$ \\
\hline $22-28$ & $11(0.02 \%)$ & $31(0.01 \%)$ & $2.12(1.06$ to 4.21$)$ \\
\hline$>28$ & $816(1.28 \%)$ & $3706(0.98 \%)$ & 1.33 (1.23 to 1.43 ) \\
\hline \multicolumn{4}{|l|}{ TCAs } \\
\hline \multicolumn{4}{|l|}{ Any TCA } \\
\hline $0 \dagger$ & $9(0.01 \%)$ & $25(0.01 \%)$ & 2.28 (1.06 to 4.88 ) \\
\hline $1-7$ & $50(0.08 \%)$ & $148(0.04 \%)$ & $2.07(1.50$ to 2.86$)$ \\
\hline $8-14$ & $49(0.08 \%)$ & $152(0.04 \%)$ & 2.02 (1.46 to 2.78 ) \\
\hline $15-21$ & $62(0.1 \%)$ & $170(0.04 \%)$ & 2.24 (1.68 to 3.01$)$ \\
\hline $22-28$ & $48(0.08 \%)$ & $157(0.04 \%)$ & 1.89 (1.37 to 2.62$)$ \\
\hline \multirow{2}{*}{\multicolumn{4}{|c|}{ Dothiepin }} \\
\hline & & & \\
\hline $0+$ & $4(0.01 \%)$ & $12(0 \%)$ & 2.05 (0.66 to 6.37$)$ \\
\hline $1-7$ & $20(0.03 \%)$ & $64(0.02 \%)$ & $1.90(1.15$ to 3.14$)$ \\
\hline $8-14$ & $21(0.03 \%)$ & $68(0.02 \%)$ & 1.88 (1.15 to 3.07$)$ \\
\hline $15-21$ & $22(0.03 \%)$ & $76(0.02 \%)$ & $1.77(1.10$ to 2.84$)$ \\
\hline $22-28$ & $16(0.03 \%)$ & $69(0.02 \%)$ & $1.42(0.83$ to 2.46$)$ \\
\hline$>28$ & $2843(4.48 \%)$ & $13142(3.47 \%)$ & 1.32 (1.26 to 1.38$)$ \\
\hline \multicolumn{4}{|l|}{ Amitriptyline } \\
\hline $0+$ & $0(0 \%)$ & $11(0 \%)$ & \\
\hline $1-7$ & $25(0.04 \%)$ & $59(0.02 \%)$ & 2.53 (1.58 to 4.05$)$ \\
\hline $8-14$ & $22(0.03 \%)$ & $70(0.02 \%)$ & $1.92(1.19$ to 3.11$)$ \\
\hline $15-21$ & $23(0.04 \%)$ & $55(0.01 \%)$ & $2.42(1.48$ to 3.95$)$ \\
\hline $22-28$ & $14(0.02 \%)$ & $69(0.02 \%)$ & $1.23(0.69$ to 2.19$)$ \\
\hline$>28$ & $2543(4.0 \%)$ & 11236 (2.97\%) & 1.38 (1.32 to 1.44$)$ \\
\hline \multicolumn{4}{|l|}{ Lofepramine } \\
\hline $0+$ & $6(0.01 \%)$ & $5(0 \%)$ & 7.25 (2.21 to 23.75$)$ \\
\hline $1-7$ & $12(0.02 \%)$ & $29(0.01 \%)$ & $2.52(1.29$ to 4.94$)$ \\
\hline $8-14$ & $12(0.02 \%)$ & $29(0.01 \%)$ & 2.53 (1.29 to 4.96$)$ \\
\hline $15-21$ & $19(0.03 \%)$ & $39(0.01 \%)$ & $2.97(1.71$ to 5.13$)$ \\
\hline $22-28$ & $14(0.02 \%)$ & $27(0.01 \%)$ & 3.02 (1.57 to 5.79 ) \\
\hline$>28$ & $1331(2.1 \%)$ & $5518(1.46 \%)$ & 1.46 (1.37 to 1.55$)$ \\
\hline
\end{tabular}

observed increases were not specific to SSRI or TCA exposure or to any individual drugs within these families in the results of either analysis strategy. Reassuringly, the self controlled method showed that there was no increased risk of MI with prolonged antidepressant exposure. This method also showed an increased risk of MI on withdrawal from antidepressant drugs, which may be a specific drug effect or may alternatively be due to discontinuing treatment as a result of worsening cardiovascular symptoms and development of other new illnesses.

\section{Strengths and limitations of the study}

Our use of the GPRD allowed us to study a real life clinical setting, rather than an experimental one, and provided considerable statistical power to detect possible small effects of individual antidepressant drugs, as well as the impact of exposure during short time periods after new exposure. Exposure misclassification in our study is unlikely, since GPRD practices record at least $95 \%$ of prescriptions, which are mostly computer generated..$^{29}$ Our finding of TCA drugs being more commonly prescribed than SSRIs was not surprising, considering that our case ascertainment spanned from 1988 to 2001 and that prescriptions shifted towards SSRI drugs over the late 1990s. We also found that, despite a suggested contraindication of TCA drugs after an MI event, both TCAs and SSRIs were prescribed after these events, which has also been found elsewhere. ${ }^{18}$

The validity of acute vascular outcomes, including acute MI, has also been found to be high in previous studies of GPRD data. ${ }^{30}{ }^{35}$ By using criteria based on the results of ECGs and cardiac enzyme assays, characteristic history, or the receipt of fibrinolytic drugs, a recorded diagnosis of MI was confirmed in over $90 \%$ of 450 cases of MI recorded in the GPRD. ${ }^{30-32}$ It is possible, however, that there is some random misclassification of the event date, since the majority of MI events are diagnosed in hospital. There may also be some systematic misclassification of event date, since a patient consulting for depression provides an opportunity for further 
Table 4 Case series analysis: association between new antidepressant exposure episode and first $\mathrm{MI}$

\begin{tabular}{|c|c|c|c|}
\hline Drug exposure period & No of cases & $\begin{array}{l}\text { No of } \\
\text { first Mls }\end{array}$ & IRR $(95 \% \mathrm{CI})$ \\
\hline SSRIs & 4132 & & \\
\hline \multicolumn{4}{|l|}{ Any SSRI } \\
\hline Day of first prescription & & 13 & $4.76(2.76$ to 8.18$)$ \\
\hline 1-7 days* & & 37 & $1.94(1.40$ to 2.68$)$ \\
\hline $8-14$ days* & & 25 & $1.31(0.89$ to 1.95$)$ \\
\hline $15-21$ days* & & 24 & $1.27(0.85$ to 1.90$)$ \\
\hline $22-28$ days* & & 22 & $1.18(0.77$ to 1.79$)$ \\
\hline Remaining exposure $\dagger$ & & 284 & $0.96(0.83$ to 1.12$)$ \\
\hline Withdrawal period $\neq$ & & 119 & $1.82(1.51$ to 2.19$)$ \\
\hline Unexposed period & & 3608 & 1.00 \\
\hline Fluoxetine & 2121 & & \\
\hline Day of first prescription & & 10 & 7.23 (3.88 to 13.46$)$ \\
\hline 1-7 days* & & 16 & $1.66(1.01$ to 2.71$)$ \\
\hline $8-14$ days* & & 14 & $1.46(0.86$ to 2.47$)$ \\
\hline $15-21$ days* & & 12 & $1.25(0.71$ to 2.21$)$ \\
\hline $22-28$ days* & & 12 & $1.26(0.71$ to 2.23$)$ \\
\hline Remaining exposure $†$ & & 125 & $0.96(0.77$ to 1.20$)$ \\
\hline Withdrawal period $\neq$ & & 63 & 1.84 (1.43 to 2.37$)$ \\
\hline Unexposed period & & 1869 & 1.00 \\
\hline Paroxetine & 1619 & & \\
\hline Day of first prescription & & 3 & 3.04 (0.98 to 9.43$)$ \\
\hline $1-7$ days* & & 18 & 2.61 (1.64 to 4.17 ) \\
\hline $8-14$ days* & & 11 & 1.61 (0.89 to 2.91$)$ \\
\hline $15-21$ days* & & 11 & 1.62 (0.89 to 2.94$)$ \\
\hline $22-28$ days* & & 11 & $1.64(0.91$ to 2.98$)$ \\
\hline Remaining exposure $†$ & & 98 & $0.94(0.73$ to 1.21$)$ \\
\hline Withdrawal period $\ddagger$ & & 46 & 1.94 (1.44 to 2.62$)$ \\
\hline Unexposed period & & 1421 & 1.00 \\
\hline \multicolumn{4}{|l|}{ TCAs } \\
\hline Any TCA & 6735 & & \\
\hline Day of first prescription & & 9 & 1.81 (0.94 to 3.47 ) \\
\hline $1-7$ days* & & 50 & 1.44 (1.09 to 1.90$)$ \\
\hline $8-14$ days* & & 49 & 1.41 (1.07 to 1.87 ) \\
\hline $15-21$ days* & & 62 & $1.80(1.40$ to 2.31$)$ \\
\hline $22-28$ days* & & 48 & $1.40(1.05$ to 1.86$)$ \\
\hline Remaining exposure $†$ & & 805 & $0.96(0.86$ to 1.09$)$ \\
\hline Withdrawal period $\ddagger$ & & 284 & $2.32(2.05$ to 2.62$)$ \\
\hline Unexposed period & & 5428 & 1.00 \\
\hline Dothiepin & 2848 & & \\
\hline Day of first prescription & & 4 & $2.00(0.75$ to 5.32$)$ \\
\hline 1-7 days* & & 20 & $1.43(0.92$ to 2.22$)$ \\
\hline $8-14$ days $^{*}$ & & 21 & $1.50(0.98$ to 2.31$)$ \\
\hline 15-21 days* & & 22 & 1.58 (1.04 to 2.41$)$ \\
\hline $22-28$ days* & & 16 & $1.16(0.71$ to 1.89$)$ \\
\hline Remaining exposure $\dagger$ & & 274 & $0.83(0.69$ to 1.00$)$ \\
\hline Withdrawal period & & 108 & $2.15(1.76$ to 2.61$)$ \\
\hline Unexposed period & & 2383 & 1.00 \\
\hline Amitriptyline & 2928 & & \\
\hline Day of first prescription & & 0 & \\
\hline 1-7 days* & & 25 & 1.85 (1.24 to 2.75$)$ \\
\hline 8-14 days* & & 22 & 1.63 (1.07 to 2.49$)$ \\
\hline $15-21$ days* & & 23 & 1.71 (1.14 to 2.59$)$ \\
\hline $22-28$ days* & & 14 & $1.05(0.62$ to 1.78$)$ \\
\hline Remaining exposure $†$ & & 270 & $1.05(0.86$ to 1.27$)$ \\
\hline Withdrawal period $\ddagger$ & & 105 & 2.21 (1.81 to 2.69$)$ \\
\hline Unexposed period & & 2469 & 1.00 \\
\hline Lofepramine & 1628 & & \\
\hline Day of first prescription & & 6 & 5.35 (2.40 to 11.91$)$ \\
\hline 1-7 days* & & 12 & $1.53(0.87$ to 2.71$)$ \\
\hline 8-14 days* & & 12 & $1.55(0.87$ to 2.73$)$ \\
\hline $15-21$ days* & & 19 & $2.47(1.56$ to 3.88$)$ \\
\hline $22-28$ days* & & 14 & $1.84(1.08$ to 3.12$)$ \\
\hline Remaining exposure $†$ & & 109 & $1.14(0.87$ to 1.49$)$ \\
\hline Withdrawal period $\ddagger$ & & 48 & 1.71 (1.28 to 2.29$)$ \\
\hline Unexposed period & & 1408 & 1.00 \\
\hline
\end{tabular}

questions from the general practitioner and may, therefore, have past diagnoses of MI recorded during the same consultation. This extra recording of MI diagnoses is likely to have the greatest effect on the day of first prescription and shortly after, and it is unlikely to have much effect in the more prolonged remaining exposure period. Thus, if present, this bias may partially explain our findings of a transient increase in risk of acute MI associated with antidepressant use. People experiencing worsening prodromal angina symptoms or post-MI depression may also be more likely to consult the general practitioner and be prescribed an antidepressant in the short period surrounding the MI. Such bias would also lead to a spurious transient association between acute MI and antidepressant exposure. 
Another methodological drawback of the classic casecontrol approach is the issue of missing data in general practice records. When we excluded patients with missing data on health measures (such as smoking status) from the case-control analyses, however, odds ratios were largely unchanged. The presence of missing data does not affect the case series method, however, since it is essentially self controlled. Thus, the case series method has the additional advantage of removing any possible residual confounding by variables that are not included in general practice records such as the severity of depression, extent of coronary artery disease, and socioeconomic status. For this reason, we believe the case series estimates are closer to the true effect size. A limitation of both the case series approach and the casecontrol approach, however, is that they cannot control for factors when they change with time, such as the improvement of depression with treatment and new co-morbidity. In the acute risk periods after a first prescription (0-28 days) risk estimates are probably independent of any changes in the severity of depression, since depressive symptoms are usually unchanged during this initial exposure period. In the remaining exposure and withdrawal periods, however, we cannot rule out possible confounding by changing severity of depression or cardiovascular health. Therefore, while an independent risk of acute MI may be associated with withdrawal from any antidepressant, an alternative explanation is that people discontinued antidepressant treatment as a result of worsening cardiovascular symptoms or health in general.

\section{Comparison with other studies}

Previous studies have found no increased risk of MI with exposure to SSRI antidepressants ${ }^{13}{ }^{16-19}$ but some have found an increased risk with TCA exposure. ${ }^{15}{ }^{17}$ Our results for TCA drugs in the case-control analysis are similar to results of these studies, but the more conservative case series estimates suggest that part of the explanation for these results is residual confounding. It is likely that such problems were also present in previous studies. In two small case-control studies, Thorogood et al ${ }^{15}$ found an increased risk of fatal MI in women with prior TCA exposure, whereas Sauer et al ${ }^{13}$ found a decreased risk of hospitalisation for first MI with previous SSRI exposure but no association with exposure to other antidepressants, which included TCA drugs. A further study by Sauer $e t a l^{16}$ found the same conclusions in a larger sample of 1080 cases and 4256 controls, of whom only 223 were taking SSRI antidepressants. A cohort study of hospitalisation and death from MI over four years similarly found an increased risk for TCA exposure but no association with SSRI exposure. ${ }^{17}$ In contrast, both a database study of prescribing in general practice and a large case-control study found no increased risk of MI associated with antidepressants in either family of drugs. ${ }^{18}{ }^{19}$ Most studies of acute MI have been too small to investigate effects of individual drugs. However, these individual effects have been explored with IHD rather than acute MI as an outcome. In a case-control study, Hippisley-Cox et $a l^{20}$ found an increased risk of IHD with TCA drugs but not with SSRIs; within the TCA drug family, the strongest association was found with dothiepin, although there was also an increased risk with lofepramine. In our study, we did not replicate these specific drug effects. The reasons for inconsistent results from studies of MI and IHD are not clear but include limited statistical power in some studies, the presence of depression as a likely confounder, ${ }^{21} 2326$ the varying severity of underlying depression, and prescribing bias (or indication bias) resulting from preferential prescribing of certain antidepressants and not others, based on the general practitioner's assessment of the patient's cardiovascular risk status.

\section{Clinical implications}

We found a transient increased risk of acute MI in the initial 28 days of exposure to antidepressant drugs, which did not persist after this period. This suggests that people now taking antidepressants do not need to stop taking these drugs, as no increased risk is conferred by prolonged exposure. Furthermore, the finding that the transient increased risk was not specific to TCA or SSRI drugs or to individual drugs within these families indicates that the association is unlikely to be a causal drug effect and may be due to underlying depression or health services utilisation. An increase in inflammatory activity for other physiological reasons may lead to both MI and depressive illness. The increased risk of MI on withdrawal from antidepressant drugs, however, warrants further investigation for a clinical explanation. While this may be a specific drug effect, it may reflect a discontinuation of treatment as a result of worsening cardiovascular symptoms or the development of other illness.

\section{ACKNOWLEDGEMENTS}

We thank Dr Julia Hippisley-Cox and Professor Mike Pringle from the Division of Primary Care, University of Nottingham for their valuable advice during the project and comments on the manuscript.

\section{Authors' affiliations}

L J Tata, J West, T Card, R Hubbard, Division of Epidemiology and Public Health, University of Nottingham, Nottingham, UK

C Smith, Respiratory Medicine, Nottingham City Hospital, Nottingham, UK

P Farrington, Statistics, The Open University, Milton Keynes, UK L Smeeth, Epidemiology and Population Health, London School of Hygiene \& Tropical Medicine, London, UK

Source of funding: Junior Research Fellowship for L J Tata, School of Community Health Sciences, University of Nottingham

\section{REFERENCES}

1 Anon. Key health statistics from general practice 1996. London: Office for National Statistics, 1998:44-7.

2 Anderson IM. Selective serotonin reuptake inhibitors versus tricyclic antidepressants: a meta-analysis of efficacy and tolerability. J Affect Disord 2000;58:19-36.

3 Martin RM, Hilton SR, Kerry SM, et al. General practitioners' perceptions of the tolerability of antidepressant drugs: a comparison of selective serotonin reuptake inhibitors and tricyclic antidepressants. BMJ 1997;314:646-51

4 Lawrenson RA, Tyrer F, Newson RB, et al. The treatment of depression in UK general practice: selective serotonin reuptake inhibitors and tricyclic antidepressants compared. J Affect Disord 2000;59:149-57.

5 Geddes JR, Freemantle N, Mason J, et al. Selective serotonin reuptake inhibitors (SSRIs) for depression (Cochrane review). Cochrane Library 2003(2):CD001851

6 MacGillivray S, Arroll B, Hatcher S, et al. Efficacy and tolerability of selective serotonin reuptake inhibitors compared with tricyclic antidepressants in depression treated in primary care: systematic review and meta-analysis. BMJ 2003;326:1014.

7 Furukawa TA, McGuire H, Barbui C. Meta-analysis of effects and side effects of low dosage tricyclic antidepressants in depression: systematic review. BMJ 2002;325:991.

8 Carney RM, Freedland KE, Veith RC, et al. Can treating depression reduce mortality after an acute myocardial infarction? Psychosom Med 1999;61:666-75

9 Henry JA, Alexander CA, Sener EK. Relative mortality from overdose of antidepressants. BMJ 1995;310:221-4

10 Movig KL, Janssen MW, de Waal Malefiit J, et al. Relationship of serotonergic antidepressants and need for blood transfusion in orthopedic surgical patients. Arch Intern Med 2003; 163:2354-8.

11 Serebruany VL, Glassman AH, Malinin Al, et al. Selective serotonin reuptake inhibitors yield additional antiplatelet protection in patients with congestive heart failure treated with antecedent aspirin. Eur J Heart Fail 2003;5:517-21.

12 Serebruany VL, Glassman AH, Malinin Al, et al. Platelet/endothelial biomarkers in depressed patients treated with the selective serotonin reuptake inhibitor sertraline after acute coronary events: the sertraline antidepressant heart attack randomized trial (SADHART) platelet substudy. Circulation 2003; 108:939-44

13 Saver WH, Berlin JA, Kimmel SE. Selective serotonin reuptake inhibitors and myocardial infarction. Circulation 2001;104:1894-8.

14 de Abajo FJ, Rodriguez LA, Montero D. Association between selective serotonin reuptake inhibitors and upper gastrointestinal bleeding: population based case-control study. BMJ 1999;319:1106-9. 
15 Thorogood M, Cowen P, Mann J, et al. Fatal myocardial infarction and use of psychotropic drugs in young women. Lancet 1992;340:1067-8.

16 Saver WH, Berlin JA, Kimmel SE. Effect of antidepressants and their relative affinity for the serotonin transporter on the risk of myocardial infarction. Circulation 2003;108:32-6.

17 Cohen HW, Gibson G, Alderman MH. Excess risk of myocardial infarction in patients treated with antidepressant medications: association with use of tricyclic agents. Am J Med 2000;108:2-8.

18 MacDonald TM, McMahon AD, Reid IC, et al. Antidepressant drug use in primary care: a record linkage study in Tayside, Scotland. BMJ 1996;313:860-1.

19 Meier CR, Schlienger RG, Jick H. Use of selective serotonin reuptake inhibitors and risk of developing first-time acute myocardial infarction. $\mathrm{Br} J \mathrm{Clin}$ Pharmacol 2001;52:179-84.

20 Hippisley-Cox J, Pringle M, Hammersley V, et al. Antidepressants as risk factor for ischaemic heart disease: case-control study in primary care. BMJ 2001;323:666-9

21 Pratt LA, Ford DE, Crum RM, et al. Depression, psychotropic medication, and risk of myocardial infarction. Prospective data from the Baltimore ECA followup. Circulation 1996:94:3123-9.

22 Tyrer F, Lawrenson R, Farmer RD. A study of cardiovascular disease, depression and antidepressants on a computerised general practice database. Hum Psychopharmacol Clin Exp 1999;14:233-7.

23 Hippisley-Cox J, Fielding K, Pringle M. Depression as a risk factor for ischaemic heart disease in men: population based case-control study. BMJ 1998;316:1714-9.

24 Lesperance F, Frasure-Smith N, Talajic M. Major depression before and after myocardial infarction: its nature and consequences. Psychosom Med 1996;58:99-110.
25 Cohen HW Madhavan S, Alderman MH. History of treatment for depression: risk factor for myocardial infarction in hypertensive patients. Psychosom Med 2001;63:203-9.

26 Barefoot JC, Schroll M. Symptoms of depression, acute myocardial infarction, and total mortality in a community sample. Circulation 1996;93:1976-80.

27 EPIC. The General Practice Research Database: a guide for researchers. London: EPIC, 2001

28 Lawson DH, Sherman V, Hollowell J. The General Practice Research Database. Scientific and Ethical Advisory Group. Q J M 1998;91:445-52.

29 Lawrenson R, Williams T, Farmer R. Clinical information for research: the use of general practice databases. J Public Health Med 1999:21:299-304.

30 Meier CR, Jick SS, Derby LE, et al. Acute respiratory-tract infections and risk of first-time acute myocardial infarction. Lancet 1998;351:1467-71.

31 Jick H, Derby LE, Gurewich V, et al. The risk of myocardial infarction associated with antihypertensive drug treatment in persons with uncomplicated essential hypertension. Pharmacotherapy 1996;16:321-6.

32 Jick H, Vasilakis C, Derby LE. Antihypertensive drugs and fatal myocardial infarction in persons with uncomplicated hypertension. Epidemiology 1997;8:446-8.

33 Garcia Rodriguez LA, Perez Gutthann S. Use of the UK General Practice Research Database for pharmacoepidemiology. Br J Clin Pharmacol 1998;45:419-25.

34 Farrington CP, Nash J, Miller E. Case series analysis of adverse reactions to vaccines: a comparative evaluation. Am J Epidemiol 1996; 143:1 165-73.

35 Lawrenson $\mathbf{R}$, Todd JC, Leydon GM et al. Validation of the diagnosis of venous thromboembolism in general practice database studies. $\mathrm{Br} J \mathrm{Clin}$ Pharmacol 2000;49:591-6.

\section{IMAGES IN CARDIOLOGY}

\section{The accordion phenomenon}

A 65 year old man, with a history of non-insulin dependent diabetes, arterial hypertension, hyperlipidaemia, and coronary artery bypass graft surgery, presented with crescendo angina. Salient features on angiography include a normal left ventricular function (ejection fraction $82 \%$ ), occlusion of the mid left anterior descending (LAD) artery, a 70\% proximal stenosis in the first marginal, and occlusion of the second marginal branch of the left circumflex artery (panel A), occlusion of the left internal mammary graft to the first marginal, and a patent right internal mammary graft to the LAD. Percutaneous coronary intervention (PCI) to the first marginal branch was performed. Because of the tortuosity of the vessel, a 6 French Left Amplatz 2 guiding catheter and a heavyweight guide wire (ACS Hi-Torque) were chosen to successfully cross the stenosis. The stenosis was predilated up to $18 \mathrm{~atm}$ (Mercury $2.5 \times 20 \mathrm{~mm}$ balloon, Jomed) and a drug eluting stent (Taxus $3.5 \times 24 \mathrm{~mm}$ ) was deployed at $18 \mathrm{~atm}$. Angiography revealed a good result at the stented segment
(10\% stenosis); however, a new long 70\% stenotic lesion just distal to the stent was observed (panel B). Administration of intracoronary glyceryl trinitrate had no effect. This "virtual stenosis", however, disappeared when the guide wire was withdrawn (panel C), with the final angiography showing a good result with a normal distal vessel.

This case demonstrates the "accordion" or "concertina" phenomenon, caused usually by mechanical alteration of the geometry and curvature of a tortuous vessel by a stiff PCI wire, resulting in invagination and shortening of the vessel wall. The importance of recognising this cannot be overstated, as it stops unnecessary further PCI to an otherwise normal coronary segment.
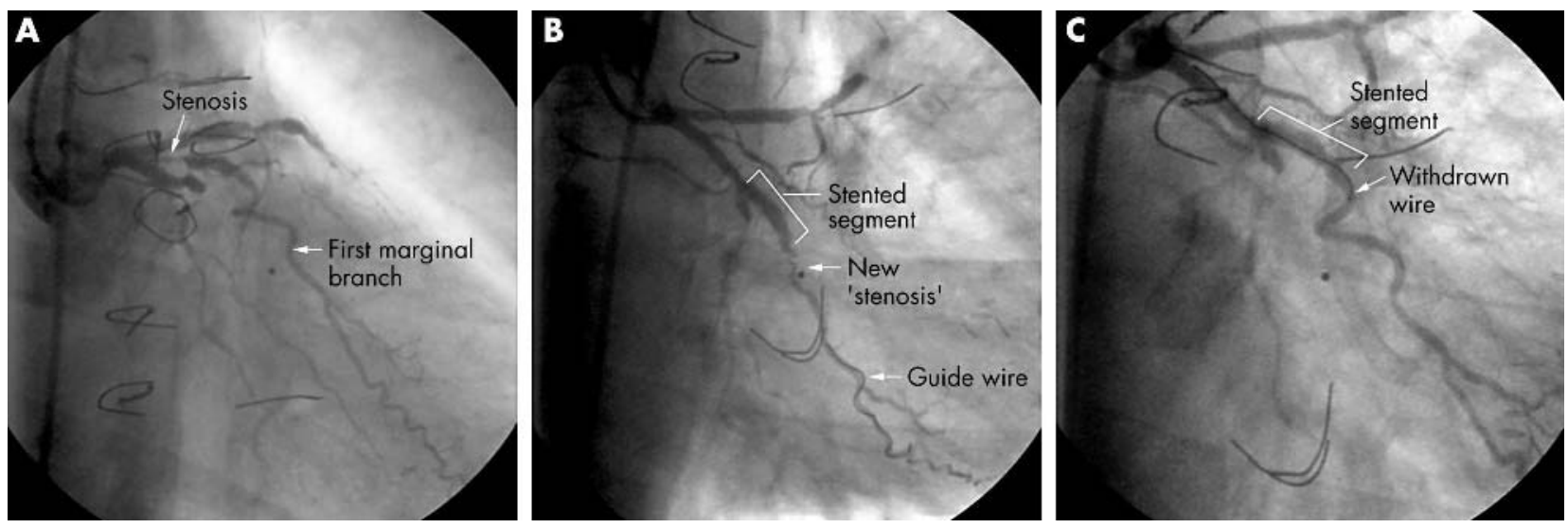